\title{
Upper aerodigestive cancer in battery manufacturers and steel workers exposed to mineral acid mists
}

\author{
David Coggon, Brian Pannett, Graham Wield
}

\begin{abstract}
Objective-To assess the risk of cancer from inhalation of mineral acid mists. Methods-A cohort study and nested case-control study of upper aerodigestive tumours were carried out in men employed since 1950 at two battery plants and two steel works in Britain. The cohort was identified from personnel records and included 2678 men with definite exposure to acid mists (mainly sulphuric acid), 367 with possible exposure, and 1356 who were unexposed. Mortality was compared with that in the national population by the person-years method. Cases of upper aerodigestive cancer were identified from death certificates and cancer registrations, and their exposure to acids was compared with that of age matched controls (five per case) from the same plant by conditional logistic regression. Results-In follow up to 31 December $1993,93 \%$ of men were traced, including 1277 who had died. Among the men definitely exposed to acid mists, overall mortality was less than in the national population (standardised mortality ratio (SMR) 0.92, 95\% confidence interval (95\% CI) $0.85-0.98$ ) as was mortality from all cancers (SMR 0.92, 95\% CI 0.79-1.05) and specifically from cancer of the larynx (SMR 0.48, 95\% CI 0.01-2.70) and lung (SMR 0.98, 95\% CI 0.78-1.22). A total of 15 incident or fatal cases of upper aerodigestive cancer were identified during follow up. When these men were compared with controls, risk was moderately increased in those who had worked for at least five years in jobs entailing exposures to sulphuric or hydrochloric acid in excess of $1 \mathrm{mg} / \mathrm{m}^{3}$ (OR $2 \cdot 0,95 \%$ CI 0.4-10).
\end{abstract}

Conclusions-These findings are consistent with those from other studies which have indicated a hazard of upper aerodigestive cancer from acid mists. However, they indicate that any risk from exposures to sulphuric and hydrochloric acid below $1 \mathrm{mg} / \mathrm{m}^{3}$ is small.

(Occup Environ Med 1996;53:445-449)

Keywords: acid mists; cancer; larynx; aerodigestive

Sulphuric, hydrochloric, and other mineral acids are widely used in industry. ${ }^{1}$ Mists formed by such acids are irritant to the upper airways, ${ }^{2}$ and at high concentrations cause erosion of dental enamel. ${ }^{34}$ Over the past 15 years, evidence has accumulated that they can also cause upper aerodigestive cancer and particularly cancer of the larynx. Thus, in 1981 Ahlborg and colleagues reported three cases of laryngeal cancer among 110 men employed for more than a year at a Swedish plant where sulphuric, nitric, and oxalic acids had been used to pickle steel pipes. ${ }^{5}$ Subsequently, an excess of laryngeal cancers was found in a cohort of steel workers in the United States who were exposed to mists, mainly of sulphuric acid ${ }^{6}$; and an increased incidence of laryngeal tumours was found in men exposed to sulphuric acid at an Italian soap factory. ${ }^{8}$ Exposure to sulphuric acid has also occurred in the manufacture of ethanol and isopropanol, where studies have suggested an increased risk both of laryngeal and other upper aerodigestive cancers..$^{913}$ In particular, a case-control study among employees at an ethanol plant in the United States found a fourfold increase in the risk of upper respiratory cancer in workers with potentially high exposure to sulphuric acid, and an even bigger relative risk for laryngeal cancer specifically. ${ }^{14}$

These findings from investigations in industry are supported by three case-control studies of laryngeal cancer in the general population carried out in Gliwice, Poland, ${ }^{15}$ Ontario, Canada, ${ }^{16}$ and Buffalo, New York ${ }^{17}$; although another case-control study in Texas found no association between laryngeal carcinoma and potential exposure to sulphuric acid. ${ }^{18}$

Largely on the basis of this evidence, the International Agency for Research on Cancer has classified occupational exposure to strong inorganic acid mists containing sulphuric acid as carcinogenic in humans. ${ }^{1}$ To control the hazard, however, more information is needed about the relation of risk to level and duration of exposure. We describe here a cohort study and a nested case-control study which examine further the risk of upper aerodigestive cancer from mineral acid mists.

\section{Method}

COHORT STUDY

The cohort was identified from personnel records at two battery manufacturers (factories $A$ and B) and two steel works (factories C and D) in Britain. Factory A was established in 1914, and exposure to sulphuric acid occurred principally in the formation and charging processes. Fixed site monitoring of sulphuric 
acid was carried out sporadically in these departments from the mid 1970s, with concentrations mainly in the range $0.1-0.7$ $\mathrm{mg} / \mathrm{m}^{3}$. Before enclosure and ventilation were improved in 1967, concentrations would have been higher. Other hazardous exposures included crocidolite asbestos, lead, stibine, and pitch.

Factory B began making batteries in 1929 , and again exposure to sulphuric acid occurred in formation and charging. Fixed site monitoring during 1970-90 showed concentrations of sulphuric acid that were mostly in the range $0.4-2.0 \mathrm{mg} / \mathrm{m}^{3}$. Other exposures included crocidolite and chrysotile asbestos, lead, stibine, and pitch.

Factory C opened in 1948 and made various steel products, but mostly flat rolled steel. Sulphuric acid was used to clean steel before plating and galvanising. Although on the pickling lines the use of sulphuric acid was phased out by 1967 in favour of hydrochloric acid, it continued to be used in the hot sheet finishing and plating areas. No hygiene measurements of acid mists were available, but we were told that before 1960 some people were unable to tolerate the levels in certain areas. Exposure to asbestos may have occurred elsewhere on the site, but within the pickling areas there were no obvious confounding exposures.

Factory D began operations in 1945, also producing flat rolled steel, and initially sulphuric ac:d was used to clean the metal by a batch method. A continuous pickling process was later introduced and ran alongside the batch process until the late 1970 s when the batch process was phased out. By 1970 hydrochloric acid was being used instead of sulphuric acid on the pickling lines, although sulphuric acid remained in use in galvanising processes. No data on acid concentrations were available for this factory.

At each factory, by discussion with staff and review of files we established the date from which personnel records were complete, and abstracted the records of all men employed at any time after this date in specified jobs involving exposure to acid mists. To provide an internal control and promote heterogeneity of exposure in the nested case-control study, we also abstracted data on men who had worked during the same period in specified jobs that did not entail exposure to acids. At factory A, where personnel files were complete from 1 January 1958, the records of men who were already in employment on this date not only listed all jobs held from 1958 onwards, but also the job in which the man had worked when he first joined the company. If this first job involved exposure to acid mists, the man was included in the cohort, irrespective of his work history after 1 January 1958. Table 1 shows further details of the criteria for entry to the cohort together with the numbers enrolled from each factory.

The data abstracted for each man included his name, date of birth, National Insurance or National Health Service (NHS) number (if recorded), address, and occupational history while at the factory. At factory B, occupational health records provided an additional source of information and check on the completeness of the personnel files. A factory specific job exposure matrix was used to classify subjects according to whether they were never, possibly, or definitely exposed to acid mists. Table 1

Table 1 Description of cohort

\begin{tabular}{|c|c|c|c|c|c|c|}
\hline Factory & Industry & Subjects included in cohort & $\begin{array}{l}\text { Never exposed } \\
\text { to acid mists } \\
n\end{array}$ & $\begin{array}{l}\text { Possibly exposed } \\
\text { to acid mists } \\
n\end{array}$ & $\begin{array}{l}\text { Definitely exposed } \\
\text { to acid mists } \\
n\end{array}$ & $\begin{array}{l}\text { Total } \\
n\end{array}$ \\
\hline A & Battery manufacture & $\begin{array}{l}\text { a) All men employed during } \\
1 \text { January } 1958 \text { - } 31 \text { March } 1988 \\
\text { who worked in the formation or } \\
\text { charging departments when they } \\
\text { first joined the company or at any } \\
\text { time during that period. } \\
\text { b) All men employed during } \\
1 \text { January } 1958-31 \text { March } 1988 \\
\text { whose first job was in the casting } \\
\text { department and whose birth date } \\
\text { was divisible by three. }\end{array}$ & 5 & 6 & 405 & 416 \\
\hline B & Battery manufacture & $\begin{array}{l}\text { All men employed in the formation, } \\
\text { charging or casting departments } \\
\text { during } 1 \text { January } 1963-30 \\
\text { November } 1989\end{array}$ & 234 & 226 & 367 & 827 \\
\hline C & Steel works & $\begin{array}{l}\text { a) All men employed during } \\
1 \text { August } 1951-31 \text { August } 1990 \\
\text { who worked at some time in jobs } \\
\text { related specifically to steel pickling. } \\
\text { b) All men employed during } \\
1 \text { August } 1951-31 \text { August } 1990 \\
\text { who worked at some time in the } \\
\text { hot rolled products department } \\
\text { and who had a date of birth } \\
\text { divisible by four. }\end{array}$ & 1052 & 0 & 943 & 1995 \\
\hline D & Steel works & $\begin{array}{l}\text { All men employed during } 1 \\
\text { January } 1950-30 \text { September } 1990 \\
\text { who worked at any time: } \\
\text { a) in jobs related specifically to } \\
\text { steel pickling; } \\
\text { b) on two lines carrying out zinc } \\
\text { electroplating; } \\
\text { c) as packers, loaders, or slingers } \\
\text { in the departments carrying out } \\
\text { steel pickling. }\end{array}$ & 65 & 135 & 963 & 1163 \\
\hline \multicolumn{3}{|c|}{ All factories } & 1356 & 367 & 2678 & 4401 \\
\hline
\end{tabular}


Table 2 Outcome of follow up

\begin{tabular}{lclcr}
\hline & $\begin{array}{l}\text { Never exposed } \\
\text { to acid mists }\end{array}$ & $\begin{array}{l}\text { Possibly exposed } \\
\text { to acid mists }\end{array}$ & $\begin{array}{l}\text { Definitely exposed } \\
\text { to acid mists }\end{array}$ & Total \\
\hline Alive at 31 December 1993 & 803 & 189 & 1716 & 2708 \\
Died & 420 & 123 & 734 & 1277 \\
Emigrated or otherwise lost & 32 & 12 & 65 & 109 \\
Untraced & 101 & 43 & 163 & 307 \\
Total & 1356 & 367 & 2678 & 4401 \\
\hline
\end{tabular}

shows the count of subjects in each of the exposure categories by factory. The uncertainty about possibly exposed men arose from incomplete information about the jobs that they had done.

The cohort was traced through the NHS central register, and details were obtained of any deaths, cancers, and emigrations registered during follow up to 31 December 1993. Causes of death and registered cancers were coded to the ninth revision of the international classification of diseases (ICD-9). The mortality of cohort members was compared with that of the national population by the person-years method, with age and calendar period stratified in five-year bands ${ }^{19}$ (national death rates before 1979 were reclassified to ICD-9 by use of bridging codes). Confidence intervals (CIs) were based on the Poisson distribution.

\section{NESTED CASE-CONTROL STUDY}

The cases comprised all men in the cohort with upper aerodigestive cancer (ICD-9 $140-141,143-149,160-161$ ) registered during life or recorded as an underlying or contributing cause of death before 31 December 1993. The date of diagnosis was taken as the date of cancer registration or death, whichever came earlier. For each case we selected five controls, who worked at the same factory, who were members of the cohort and under follow up at the time the case was diagnosed, and who were matched to the case as closely as possible for date of birth. The occupational histories of the cases and controls (censored five years before the date of diagnosis of the case) were reviewed by one of us (BP), blind to their case or control status, and each man was classified according to his likely exposure to acid mists, and to two possible confounders, asbestos and lead. We distinguished three levels of exposure to acids-zero, low (< $1 \mathrm{mg} / \mathrm{m}^{3}$ sulphuric or hydrochloric acid), and high ( $\geqslant 1 \mathrm{mg} / \mathrm{m}^{3}$ sulphuric or hydrochloric acid), taking into account the time periods during which jobs had been held. At factories $\mathrm{C}$ and $\mathrm{D}$, where no hygiene data were available, the distinction between jobs with high and low exposure was based on concentrations recorded at other similar plants. Because information about some jobs was incomplete, the exposures of a few men were classed as uncertain.

Associations of upper aerodigestive cancer with exposure to acid mists and potentially confounding carcinogens were examined by conditional logistic regression for matched sets. $^{20}$

\section{Results}

In total the cohort comprised 4403 men, but two were excluded from the analysis because their date of first employment was unknown. Table 1 shows the distribution of the remaining 4401 subjects by factory. On the basis of their job histories, 1356 men were classified as never exposed to acid mists, 367 as possibly exposed, and 2678 as definitely exposed.

Table 2 summarises the outcome of follow up. Three hundred and seven men (7\%) were untraced and were followed up to their last known date of employment. Follow up of emigrants was censored at their date of migration.

Table 3 shows the cause specific mortality of the cohort according to exposure. Overall mortality was lower than in the national population (1277 deaths, SMR 0.94, 95\% CI $0.89-0.99)$, as was that from most specific

Table 3 Mortality of cohort by exposure to acid mists

\begin{tabular}{|c|c|c|c|c|c|c|}
\hline \multirow{2}{*}{$\begin{array}{l}\text { Cause of death } \\
\text { (ICD-9 codes) }\end{array}$} & \multicolumn{2}{|c|}{${ }^{\star}$ Full cohort } & \multicolumn{2}{|c|}{ Never exposed to acid mists } & \multicolumn{2}{|c|}{ Definitely exposed to acid mists } \\
\hline & Deaths & $S M R(95 \% C I)$ & Deaths & $S M R(95 \% C I)$ & Death & $\operatorname{SMR}(95 \% C I)$ \\
\hline All causes (001-999) & 1277 & $0.94(0.89-0.99)$ & 420 & $0.94(0.85-1.03)$ & 730 & $0.92(0.85-0.98)$ \\
\hline All cancers $(140-208)$ & 324 & $0.88(0.79-0.98)$ & 88 & $0.74(0.59-0.91)$ & 199 & $0.92(0.79-1.05)$ \\
\hline Cancer of lip (140) & 1 & $7 \cdot 15(0 \cdot 18-39 \cdot 84)$ & 0 & $0.00(0.00-81.11)$ & 1 & $12 \cdot 58(0 \cdot 32-70 \cdot 07)$ \\
\hline Cancer of tongue (141) & 2 & $1.66(0.20-6.02)$ & 2 & $5.27(0.64-19.04)$ & 0 & $0.00(0.00-5 \cdot 18)$ \\
\hline Cancer of mouth (143-145) & 1 & $0.86(0.02-4.80)$ & 0 & $0.00(0.00-10.12)$ & 1 & $1.44(0.04-8.01)$ \\
\hline Cancer of pharynx (146-1491) & 1 & $0.41(0.01-2 \cdot 27)$ & 1 & $1.28(0.03-7 \cdot 14)$ & 0 & $0.00(0.00-2.53)$ \\
\hline Cancer of oesophagus (150) & 10 & $0.81(0.39-1.49)$ & 3 & $0.77(0.16-2.24)$ & 6 & $0.81(0.30-1.76)$ \\
\hline Cancer of stomach (151) & 31 & $0.89(0.60-1.26)$ & 8 & $0.70(0.30-1.38)$ & 17 & $0.84(0.49-1.35)$ \\
\hline Cancer of large intestine (153) & 11 & $0.47(0.23-0.84)$ & 1 & $0.13(0.00-0.73)$ & 8 & $0.57(0.25-1 \cdot 13)$ \\
\hline Cancer of rectum (154) & 16 & $0.98(0.56-1.59)$ & 4 & $0.76(0.21-1.94)$ & 11 & $1 \cdot 14(0.57-2.04)$ \\
\hline Cancer of pancreas (157) & 10 & $0.65(0.31-1 \cdot 19)$ & 3 & $0.60(0.12-1 \cdot 76)$ & 6 & $0.65(0.24-1.42)$ \\
\hline Cancer of nose $(160)$ & 0 & $0.00(0.00-5.22)$ & 0 & $0.00(0.00-16.07)$ & 0 & $0.00(0.00-8.88)$ \\
\hline Cancer of larynx (161) & 3 & $0.86(0 \cdot 18-2 \cdot 51)$ & 1 & $0.89(0.02-4.97)$ & 1 & $0.48(0.01-2 \cdot 70)$ \\
\hline Cancer of lung, pleura & & & & & & \\
\hline mediastinum (162-164) & 134 & $0.94(0.78-1.11)$ & 36 & $0.77(0.54-1.07)$ & 83 & $0.98(0.78-1 \cdot 22)$ \\
\hline Cancer of prostate (185) & 21 & $0.92(0.57-1.40)$ & 6 & $0.80(0.29-1.74)$ & 14 & $1.03(0.57-1.74)$ \\
\hline Cancer of bladder (188) & 13 & $0.93(0.49-1.58)$ & 4 & $0.87(0.24-2 \cdot 23)$ & 7 & $0.85(0.34-1.75)$ \\
\hline Cancer of kidney (189) & 6 & $0.85(0.31-1.86)$ & 2 & $0.89(0.11-3.22)$ & 3 & $0.71(0.15-2.08)$ \\
\hline Cancer of brain (191-192) & 7 & $0.76(0.31-1.58)$ & 3 & $1.02(0.21-2.97)$ & 4 & $0.73(0.20-1.87)$ \\
\hline Hodgkin's disease (201) & 6 & $2 \cdot 19(0 \cdot 81-4 \cdot 78)$ & 2 & $2 \cdot 12(0 \cdot 26-7 \cdot 66)$ & 4 & $2.54(0.69-6.49)$ \\
\hline Non-Hodgkin's lymphoma & & & & & & \\
\hline$(200,2020-2021,2028)$ & 6 & $0.82(0.30-1.79)$ & 2 & $0.85(0.10-3.07)$ & 2 & $0.46(0.05-1.65)$ \\
\hline Multiple myeloma (203) & 8 & $1.87(0.81-3.69)$ & 4 & $2.91(0.79-7.46)$ & 4 & $1.56(0.43-3.99)$ \\
\hline Leukaemia (204-208) & 7 & $0.78(0.31-1.61)$ & 1 & $0.34(0.01-1.88)$ & 5 & $0.94(0.31-2.20)$ \\
\hline Circulatory disease $(390-459)$ & 660 & $1.01(0.94-1.09)$ & 226 & $1.07(0.93-1.22)$ & 377 & $0.99(0.89-1.09)$ \\
\hline Respiratory disease $(460-519)$ & 143 & $0.92(0.78-1.09)$ & 55 & $1.07(0.81-1 \cdot 39)$ & 70 & $0.79(0.61-1.00)$ \\
\hline Injury and poisoning (800-999) & 48 & $0.76(0.56-1.01)$ & 19 & $0.87(0.53-1.36)$ & 26 & $0.71(0.47-1.05)$ \\
\hline
\end{tabular}

*The full cohort included 367 men possibly exposed to acid mists as well as those never exposed and with definite exposure. 
Table 4 Cases included in the nested case-control analysis

\begin{tabular}{llll}
\hline Factory & Site of cancer & Alive or dead & Age at diagnosis* \\
\hline A & Lip & Alive & 42 \\
B & Retromolar area & Alive & 60 \\
B & Tongue & Dead & 47 \\
C & Nasopharynx & Alive & 63 \\
C & Tonsil & Dead & 69 \\
C & Lip & Alive & 68 \\
C & Pharynx or larynxt Dead & 74 \\
C & Larynx & Alive & 55 \\
C & Gum & Dead & 67 \\
C & Tongue & Dead & 63 \\
D & Larynx & Dead & 77 \\
D & Lip & Alive & 57 \\
D & Nasal sinus & Alive & 58 \\
D & Larynx & Dead & 58 \\
D & Lip & Dead & 59 \\
\hline
\end{tabular}

*Date of death or date of cancer registration if earlier. + Squamous carcinoma of the pharynx was recorded at cancer registration, but the diagnosis on the death certificate was carcinoma of the larynx.

Table 5 Association of upper aerodigestive cancer with exposure to acid mists

\begin{tabular}{|c|c|c|c|}
\hline & $\begin{array}{l}\text { Cases } \\
n\end{array}$ & $\begin{array}{l}\text { Controls } \\
n\end{array}$ & OR $(95 \% C I)$ \\
\hline \multicolumn{4}{|l|}{ Maximum exposure to acids: } \\
\hline None & 3 & 18 & 1 \\
\hline Low & 2 & 7 & $1.9(0 \cdot 2-15 \cdot 8)$ \\
\hline High & 9 & 43 & $1 \cdot 3(0 \cdot 3-5 \cdot 7)$ \\
\hline Uncertain & 1 & 5 & $1 \cdot 0(0 \cdot 1-12)$ \\
\hline \multicolumn{4}{|l|}{ Cumulative exposure to acids: } \\
\hline None & 3 & 18 & 1 \\
\hline Intermediate or uncertain & 5 & 32 & $1 \cdot 0(0 \cdot 2-4 \cdot 6)$ \\
\hline $\begin{array}{l}\text { At least } 5 \text { years high } \\
\text { exposure }\end{array}$ & 7 & 23 & $2 \cdot 0(0.4-10)$ \\
\hline
\end{tabular}

types of cancer and from respiratory disease. Deaths from circulatory disease were close to expectation. Among men never exposed to acid mists, a similar pattern was found except that death rates from respiratory disease were higher. Mortality patterns in the men with definite exposure to acids were likewise unremarkable. In particular, there were fewer deaths than expected from cancers of the larynx (1 death, SMR 0.48) and lung (83 deaths, SMR 0.98).

Altogether, eight deaths from upper aerodigestive cancer were recorded in the cohort during the period of follow up. Also, a further seven cases were identified from cancer registrations in men still alive at the end of 1993. These 15 cases (table 4) formed the basis for the nested control analysis. The controls were tightly matched to the cases for age, with differences of less than a year for all but two controls. Two men were selected as controls twice, so that there was a total of 73 controls.

Table 5 shows the association of upper aerodigestive cancer with maximum exposure to acid mists, and with a measure of cumulative exposure. Risk was increased twofold in men who had worked for at least five years in jobs with high exposure, but this excess was not significant. Of the four men with laryngeal cancer, two were classed as having high exposure to acids for five years or more, one had intermediate or uncertain cumulative exposure, and one was unexposed. There was no association between upper aerodigestive cancer and either lead or asbestos.

\section{Discussion}

This study provides limited evidence that the risk of upper aerodigestive cancer is increased by exposure to mineral acid mists at the levels of exposure which occurred historically in the industries studied. Incidence was doubled in men who worked for more than five years in jobs where exposure to sulphuric or hydrochloric acids was likely to have exceeded $1 \mathrm{mg} / \mathrm{m}^{3}$. However, this risk estimate was based on only a small number of cases, and the excess was not significant. There was no consistent indication of any increase of risk at exposures below $1 \mathrm{mg} / \mathrm{m}^{3}$ which is the current British occupational exposure standard (OES) for sulphuric acid. Nor was there any suggestion of a notably higher risk for laryngeal than for other upper aerodigestive tumours.

As well as its low statistical power when looking at rare cancers, the study had several other limitations. The proportion of cohort members untraced at the NHS Central Register (7\%) was higher than in most investigations of this type, although there is no reason to suspect that the untraced men would have had an unusually low or high cancer incidence. Also, the data on cancer incidence are likely to have been incomplete for the early years of follow up. This is because cancer registration did not become well established in many regions of Britain until the 1970s. To avoid possible biases from regional differences in the ascertainment of cancers, we selected controls for the nested case-control analysis from the same factory as their matched case. Within the workforce of a particular factory we would not expect the completeness with which cancers were ascertained to relate in any way to work with acids.

Another problem was the possibility of confounding effects. Asbestos has been linked with laryngeal cancer in several studies, ${ }^{21}{ }^{22}$ but in our analysis it was not associated with upper aerodigestive cancer and should not have had an important confounding influence. Some of our subjects working in the manufacture of batteries were exposed to lead, but again this did not seem to be an important confounder. Of potential non-occupational confounders, the most important are alcohol and smoking, both of which are established causes of oral and laryngeal cancer. ${ }^{23}$ We had no direct information about subjects' consumption of either alcohol or tobacco, but it is notable that in contrast to one previous study, ${ }^{24}$ mortality from lung cancer among men with definite exposure to acid mists was close to expectation. Lung cancer is more strongly associated with smoking than oral or laryngeal cancer, and in view of this we think it unlikely that smoking has had a major confounding effect. Furthermore, the strength of the relation between alcohol and upper aerodigestive cancer is such that only large differences in alcohol consumption by occupation would seriously distort associations with exposure to acids.

The other weakness of our study is the lack of occupational hygiene measurements, particularly before 1970 . We are, however, confident that concentrations of acid mists during the early period were if anything higher than those recorded more recently. 
Of the previous studies that have found associations between acid mists and cancer, two have indicated increased risk at exposures to sulphuric acid below $1 \mathrm{mg} / \mathrm{m}^{3} .{ }^{716}$ Our findings do not exclude this possibility, but they suggest that any risk from this level of exposure must be small.

This study was supported by a grant from the British Occupational Health Research Foundation. We thank the staff of the NHS Central Register for their help with the tracing exercise.

1 International Agency for Research on Cancer. LARC monographs on the evaluation of carcinogenic risks to humans. Vol 54. Occupational exposures to mists and vapours from strong inorganic acids and other industrial chemicals. Lyon: IARC, 1992.

2 Fouts JR, Lippmann M, organisers. Symposium on the health effects of acid aerosols. Environ Health Perspect health effects

3 Malcolm D, Paul E. Erosion of the teeth due to sulphuric acid in the battery industry. $B r \mathcal{F}$ Ind Med 1961;18: $63-9$

4 Gamble J, Jones W, Hancock J, Meckstroth RL. Epidemiological-environmental study of lead acid battery workers. Environ Res 1984;35:30-52.

5 Ahlborg G, Hogstedt C, Sundell L, Åmen C-G. Laryngeal cancer and pickling house vapours. Scand $\mathcal{F}$ Work Environ Health 1981;7:239-40.

6 Beaumont J, Leveton J, Knox K, Bloom T, McQuiston T, Young $\mathrm{M}$, et al. Lung cancer mortality in workers exposed to sulfuric acid mist and other acid mists. $\mathcal{f}$ Natl Cancer Inst 1987;79:911-21.

7 Steenland K, Schnorr T, Beaumont J, Halperin W, Bloom $\mathrm{T}$. Incidence of laryngeal cancer and exposure to acid mists. Br F Ind Med 1988;45:766-76.

8 Forastiere F, Valensini S, Salimei E, Magliola ME, Perucci CA. Respiratory cancer among soap production workers. CA. Respiratory cancer among soap productio

9 Hueper WC. Occupational and environmental cancers of the respiratory system. Recent Results Cancer Res 1966; 3:105-7, 183.
10 Lynch J, Hanis NM, Bird MG, Murray KJ, Walsh JP. An association of upper respiratory cancer with exposure to diethyl sulfate. $\mathcal{F}$ Occup Med 1979;21:333-41.

11 Alderson MR, Rattan NS. Mortality of workers on an isopropyl alcohol plant and two MEK dewaxing plants. $\mathrm{Br} \mathcal{F}$ Ind Med 1980;37:85-9.

12 Enterline PE. Importance of sequential exposure in the production of epichlorohydrin and isopropanol. Ann NY Acad Sci 1982;381;344-9.

13 Teta MJ, Perlman GD, Ott MG. Mortality study of ethanol and isopropanol production workers at two facilities. and isopropanol production workers at

14 Soskolne CL, Zeighami EA, Hanis NM, Kupper LL, Herrmann N, Amsel J, et al. Laryngeal cancer and occupational exposu

15 Zemla B, Day N, Swiatnicka J, Banasik R. Larynx cancer risk factors. Neoplasma 1987;34:223-33.

16 Soskolne CL, Jhangri GS, Siemiatycki J, Lakhani R, Dewar $\mathrm{R}$, Burch JD, et al. Occupational exposure to sulfuric acid in Southern Ontario, Canada, in association with laryngeal cancer. Scand $\mathcal{f}$ Work Environ Health 1992;18: 225-32.

17 Cookfair D, Wende K, Michalek A, Vena J. A case-control study of laryngeal cancer among workers exposed to sulfuric acid [abstract]. Am f Epidemiol 1985;122:521.

18 Brown LM, Mason TJ, Pickle LW, Stewart PA, Buffler PA, Burau $\mathrm{K}$, et al. Occupational risk factors for laryngeal Burau K, et al. Occupational risk factors for laryngeal cancer $1960-4$.

19 Breslow NE, Day NE. Statistical methods in cancer research. Vol II-The design and analysis of cohort studies. Lyon: International Agency for Research on Cancer, 1987.

20 Breslow NE, Day NE. Statistical methods in cancer research. Vol I-The analysis of case-control studies. Lyon: International Agency for Research on Cancer, 1980

21 Smith AH, Handley MA, Wood R. Epidemiological evidence indicates asbestos causes laryngeal cancer. 7 Occup Med 1990:32:499-507.

22 Burch JD, Howe GR, Miller AB, Semenciw R. Tobacco, alcohol, asbestos, and nickel in the etiology of cancer of alcohol, asbestos, and nickel in the etiology of

23 Schottenfeld D, Fraumeni JF, eds. Cancer epidemiology and prevention. Philadelphia: WB Saunders, 1982.

24 Steenland $\mathrm{K}$, Beaumont J. Further follow-up and adjustmentand $\mathrm{K}$, Beaumont $\mathrm{J}$. Further follow-up and adjust-
ment foking in a study of lung cancer and acid mists. Am f Ind Med 1989;16:347-54.

\section{Correspondence and editorials}

Occupational and Environmental Medicine welcomes correspondence relating to any of the material appearing in the journal. Results from preliminary or small scale studies may also be published in the correspondence column if this seems appropriate. Letters should be not more than 500 words in length and contain a minimum of references. Tables and figures should be kept to an absolute minimum. Letters are accepted on the understanding that they may be subject to editorial revision and shortening.

The journal also publishes editorials which are normally specially commissioned. The Editor welcomes suggestions regarding suitable topics; those wishing to submit an editorial, however, should do so only after discussion with the Editor. 